\title{
FAKTOR FAKTOR YANG BERPENGARUH TERHADAP PRODUKSI KERUPUK MIE SINGKONG PADA INDUSTRI RUMAH TANGGA DI DESA CIKUKULU KECAMATAN KARANGNUNGGAL KABUPATEN TASIKMALAYA
}

\author{
FACTORS THAT AFFECT ON THE PRODUCTION OF Cassava Noodle Crackers \\ IN THE HOUSEHOLD INDUSTRY \\ IN CIKUKULU VILLAGE, KECAMATAN KARANGNUNGGAL, TASIKMALAYA \\ DISTRICT
}

\author{
YOPANDA ADITYA PRADINA ${ }^{1^{*}}$, DINI ROCHDIANI ${ }^{2}$, BUDI SETIA $^{1}$ \\ ${ }^{1}$ Fakultas Pertanian Universitas Galuh \\ ${ }^{2}$ Fakultas Pertanian Universitas Padjajaran \\ E-mail:yopandaaditya0@gmail.com
}

\begin{abstract}
ABSTRAK
Tujuan penelitian ini adalah menganalisis faktor - faktor yang mempengaruhi produksi kerupuk mie singkong di Desa Cikukulu Kecamatan Karangnunggal Kabupaten Tasikmalaya serta mencari faktor yang paling dominan dalam mempengaruhi produksi kerupuk mie singkong. Metode penelitian yang digunakan adalah survey, dengan subjek penelitian kepada perajin industri rumah tangga kerupuk mie singkong yang berada di Desa Cikukulu Kecamatan Karangnunggal Kabupaten Tasikmalaya. Hasil penelitian menjelaskan, bahwa secara simultan faktor modal, tenaga kerja dan bahan baku berpengaruh signifikan terhadap produksi. Sedangkan secara parsial modal dan bahan baku berpengaruh signifikan terhadap produksi, namun tenaga kerja berpengaruh tidak signifikan terhadap produksi. Faktor yang paling dominan dalam mempengaruhi produksi kerupuk mie singkong di kecamatan Cikulu Kabupaten Tasikmalaya adalah bahan baku.
\end{abstract}

Kata Kunci: Bahan Baku, Modal, Produksi, Tenaga Kerja

\section{ABSTRACT}

The purpose of this study was to determine and analyze the factors that influence the production of cassava noodle crackers in Cikukulu Village, Karangnunggal Subdistrict, Tasikmalaya Regency and to find the most dominant factor in influencing the production of cassava noodle crackers. Survey research method, with research subjects to craftsmen of the cassava noodle cracker home industry in Cikukulu Village, Karangnunggal District, Tasikmalaya Regency with quantitative descriptive analysis. The results of this study indicate that the factors that influence production are capital, labor and raw materials. The results showed that simultaneously the factors that influence production, namely capital, labor and raw materials, have a significant effect on production. While partially, capital and raw materials have a significant effect on production, but labor has no significant effect on production. The most dominant factor in influencing the production of cassava noodle crackers in Cikulu sub-district, Tasikmalaya Regency is the raw material factor.

Keywords: Raw Materials, Capital, Production, Labor

\section{PENDAHULUAN}

Kabupaten Tasikmalaya merupakan salah satu wilayah dengan struktur ekonomi masih dominan subsektor pertanian dimana sebagaian masyarakat bergantung pada subsektor pertanian dengan mengolah makanan dari hasil pertanian menjadi suaru produk barang setengah jadi yang 
siap di olah menjadi produk makanan yang siap di pasarkan, salah satunya kerupuk mie singkong dengan dukungan bahan baku dari singkong yang tersedia.

Salah satu pengolahan yang potensial dikembangkan di Desa Cikukulu Kecamatan Karangnunggal Kabupaten Tasikmalaya yaitu kerupuk mie singkong. Kerupuk mie singkong atau sering disebut oleh masyarakat kerupuk mie kuning adalah makanan ringan yang terbuat dari singkong atau ubi kayu, hal ini dapat kita lihat dengan semakin banyaknya usaha kecil menengah yang memproduksi kerupuk mie singkong. Apabila ditinjau dari aspek ekonomis usaha pembuatan kerupuk mie singkong mempunyai prospek yang menggembirakan, karena dengan harga yang terjangkau konsumen bisa menikmati makanan ringan kerupuk mie singkong.

Para perajin usaha industri rumah tangga kerupuk mie singkong. membuka usaha tersebut dengan tujuan untuk memperoleh laba dan pendapatan.

Menurut Mutiara Ayu (2010), untuk menjalankan suatu usaha dipengaruhi oleh beberapa faktor yaitu modal, tenaga kerja dan bahan baku. Demikian pula dalam usaha industri rumah tangga kerupuk mie singkong faktor- faktor tersebut akan mempengaruhi terhadap usaha produksi kerupuk mie singkong.

Faktor tenaga kerja dan modal merupakan faktor- faktor yang cenderung mempengaruhi produksi kerupuk mie singkong. Semakin besar modal maka akan semakin besar dalam membeli bahan baku mie sehingga hasil produksi yang diperoleh juga akan semakin besar.

Faktor tenaga kerja berpengaruh terhadap produksi karena apapun yang akan dikerjakan sudah pasti membutuhkan tenaga kerja. Semakin banyak tenaga kerja yang paham akan pengolahan kerupuk mie singkong maka akan semakin besar pula hasil produksi yang diperoleh.

Faktor bahan baku akan mempengaruhi produksi kerupuk mie singkong karena bahan baku merupakan kunci utama dalam proses usaha kerupuk mie tersebut, sehingga bahan baku yang digunakan dapat menentukan besar atau kecilnya hasil produksi mie. Ssemakin baik bahan baku yang digunakan akan lebih banyak kemungkinan untuk memperoleh hasil produksi usaha kerupuk mie yang lebih menguntungkan dan tentunya akan memberikan keuntungan yang lebih besar terhadap usaha kerupuk mie tersebut.

Berdasarkan uraian di atas, maka 
dalam penelitian ini menarik untuk dilakukan penelitian mengenai FaktorFaktor yang berpengaruh terhadap Produksi Kerupuk Mie Singkong pada Industri Rumah Tangga di Desa Cikukulu Kecamatan Karangnunggal Kabupaten Tasikmalaya.

Berdasarkan identifikasi masaalah tersebut di atas, maka penelitian ini bertujuan untuk mengetahui faktor modal, tenaga kerja, dan bahan baku berpengaruh terhadap produksi kerupuk mie singkong di Desa Cikukulu Kecamatan Karangnunggal Kabupaten Tasikmalaya secara simultan dan parsial.

\section{HASIL DAN PEMBAHASAN}

Faktor - Faktor yang mempengaruhi

\section{Produksi Kerupuk Mie Singkong}

Untuk mengetahui faktor - faktor yang mempengaruhi produksi pada industri rumah tangga kerupuk mie singkong di Desa Cikukulu Kecamatan Karangnunggal Kabupaten Tasikmalaya dilakukan pengolahan dengan menggunakan analisis regresi berganda. Adapun proses perhitungan data di lakukan dengan menggunakan program SPSS V.23.

Berdasarkan hasil uji statistik secara simultan mengenai faktor-faktor yang mempengaruhi produksi kerupuk mie singkong dengan menggunakan analisis regresi berganda diperoleh persamaan sebagai berikut:

Tabel 17. Persamaan Regresi

Coefficients $^{\mathrm{a}}$

\begin{tabular}{|c|c|c|}
\hline \multirow[t]{2}{*}{ Model } & \multicolumn{2}{|c|}{$\begin{array}{c}\text { Unstandardized } \\
\text { Coefficients }\end{array}$} \\
\hline & B & Std. Error \\
\hline (Constant) & 4.542 & .213 \\
\hline $\log \_X 1$ & .149 & .041 \\
\hline log_X2 & .001 & .016 \\
\hline $\log _{-} X 3$ & .948 & .022 \\
\hline
\end{tabular}

a. Dependent Variable: $\log _{-} Y$

Sumber: Data Output SPSS

$Y=4,542+0,149 X_{1}+0,001 X_{2}+$

$0,948 X_{3}+e$

Interpretasi dari persamaan regresi berganda tersebut adalah

1) Jika diasumsikan nilai dari variabel $X_{1}$ (Modal), $\mathrm{X}_{2}$ (Tenaga Kerja) dan $\mathrm{X}_{3}$ (Bahan Baku) adalah konstan atau sama dengan nol, maka nilai variabel Y (Produksi) adalah 4,542.

2) Variabel Modal $\left(X_{1}\right)$ mempunyai koefisien regresi yaitu 0,149 yang artinya jika terjadi peningkatan variabel Modal $\left(\mathrm{X}_{1}\right)$ sebesar Rp. 1,maka Produksi akan bertambah atau meningkat $0,149 \mathrm{Kg}$, dengan catatan bahwa variabel lain tetap atau konstan.

3) Variabel Tenaga kerja ( $\left.X_{2}\right)$ mempunyai koefisien regresi 0,001 yang artinya jika terjadi peningkatan variabel Tenaga kerja $\left(\mathrm{X}_{2}\right) 1$ orang, maka produksi akan bertambah atau 
meningkat sebesar $0,001 \mathrm{Kg}$, dengan catatan bahwa variabel lain tetap atau konstan.

4) Variabel Bahan baku $\left(X_{3}\right)$ mempunyai koefisien regresi 0,948 yang artinya jika terjadi peningkatan variabel Bahan baku $\left(\mathrm{X}_{3}\right)$ Rp. 1,-, maka produksi akan bertambah atau meningkat $0,948 \mathrm{Kg}$, dengan catatan bahwa variabel lain tetap atau konstan.

Uji Koefisien Determinasi. Perhitungan Uji Koefisien Determinasi dapat dilihat pada Tabel Koefesien Determninasi atau "Model Summary" sebagai berikut:

\section{Tabel 2. Koefisien Determinasi}

Model Summary ${ }^{\text {b }}$

\begin{tabular}{|l|c|r|r|}
\hline Model & $\mathrm{R}$ & R Square & $\begin{array}{c}\text { Adjusted R } \\
\text { Square }\end{array}$ \\
\hline 1 & $.998^{\mathrm{a}}$ & .996 & .996 \\
\hline
\end{tabular}

a. Predictors: (Constant), log_X3, $\log _{-} \mathrm{X} 2, \log \_\mathrm{X} 1$

b. Dependent Variable: $\log _{-} Y$

Sumber: Data Output SPSS

Pengujian koefisien determinasi $\left(\mathrm{R}^{2}\right)$ digunakan untuk mengukur proporsi atau persentase kemampuan model dalam menerangkan variabel terikat. Koefisien determinasi berkisar antara nol sampai satu $\left(0 \leq \mathrm{R}^{2} \geq 1\right)$. Jika $\mathrm{R}^{2}$ semakin besar (mendekati satu), maka dapat dikatakan bahwa pengaruh variabel bebas (X) adalah besar terhadap variabel terikat (Y). Hal ini berarti model yang digunakan semakin kuat untuk menerangkan pengaruh variabel bebas terhadap variabel terikat dan demikian sebaliknya. Berdasarkan Tabel 16 diperoleh bahwa koefisien determinasi $R$-Squared sebesar 0,996. Hal ini menunjukan bahwa keragaman variabel dependent (produksi kerupuk mie singkong) yang dimasukan ke dalam model dapat diterangkan oleh variabel independent (modal, tenaga kerja, bahan baku) mencapai $99,6 \%$ dan sisanya $0,4 \%$ diterangkan oleh variabel lain di luar model. Dengan demikian modal, tenaga kerja dan bahan baku merupakan suatu unsur penting dalam mempengaruhi produksi.

Pengujian hipotesis secara simultan menggunakan uji $\mathrm{F}$ yaitu untuk menguji apakah terdapat pengaruh secara signifikan modal, tenaga kerja dan bahan baku terhadap produksi. Besarnya pengaruh modal $\left(\mathrm{X}_{1}\right)$, tenaga kerja $\left(\mathrm{X}_{2}\right)$ dan bahan baku $\left(\mathrm{X}_{3}\right)$ terhadap produksi $(\mathrm{Y})$ dihitung dengan bantuan program SPSS versi 23.0. 
Tabel 3. Uji F

ANOVA $^{\mathrm{a}}$

\begin{tabular}{|l|c|c|}
\hline Model & F & Sig. \\
\hline Regression & 2346.382 & $.000^{\mathrm{b}}$ \\
1 Residual & & \\
Total & & \\
\hline
\end{tabular}

a. Dependent Variable: $\log _{-} Y$

b. Predictors: (Constant), log_X3, log_X2, log_X1

Berdasarkan perhitungan SPSS, diperoleh nilai signifikansi 0,000 , dengan tingkat signifikansi 0,000 yang berarti lebih kecil dari tingkat $\alpha=0,05$. Dikarenakan tingkat signifikasi lebih kecil dari 0,05 maka kaidah keputusannya modal, tenaga kerja dan bahan baku secara simultan berpengaruh signifikan terhadap produksi kerupuk mie singkong di Desa Cikukulu Kecamatan Karangnunggal Kabupaten Tasikmalaya.

Untuk menganalisis faktor-faktor yang mempengaruhi produksi kerupuk mie singkong secara parsial yaitu digunakan uji $\mathrm{t}$ parsial. Uji t parsial bertujuan untuk mengetahui besarnya pengaruh masingmasing faktor yang mempengaruhi produksi yang terdiri dari modal, tenaga kerja dan bahan baku secara individual (parsial). Hasil uji dilihat pada tabel Coefficients $^{\alpha}$ sebagai berikut:

\section{Tabel 4. Uji t}

\section{Coefficients $^{\mathrm{a}}$}

\begin{tabular}{|l|r|r|}
\hline Model & \multicolumn{1}{|c|}{$\mathrm{t}$} & Sig. \\
& & \\
\hline (Constant) & 21.285 & .000 \\
log_X1 & 3.621 & .001 \\
1 & .068 & .947 \\
log_X2 & .000 \\
log_X3 & 43.699 & \\
\hline
\end{tabular}

a. Dependent Variable: $\log _{-} \mathrm{Y}$

Sumber: Data Output SPSS

Pengaruh Modal terhadap Produksi Kerupuk Mie Singkong di Desa Cikukulu Kecamatan Karangnunggal Kabupaten Tasikmalaya

Hasil perhitungan SPSS 23.0 yang tersaji pada Tabel 20., memperlihatkan bahwa uji t untuk variabel modal diperoleh nilai signifikansi 0,001. Berdasarkan probabilitas nilai signifikansi $0,001<0,05$, berarti modal secara parsial berpengaruh siginifikan terhadap produksi kerupuk mie singkong di Desa Cikukulu Kecamatan Karangnunggal Kabupaten Tasikmalaya.

\section{Pengaruh Tenaga Kerja terhadap}

Produksi Kerupuk Mie Singkong di Desa Cikukulu

Kecamatan

Karangnunggal

Kabupaten

Tasikmalaya

Hasil perhitungan SPSS 23.0 yang tersaji pada Tabel 4., memperlihatkan bahwa uji $\mathrm{t}$ untuk variabel tenaga kerja diperoleh nilai 
signifikansi $\quad 0,947 . \quad$ Berdasarkan probabilitas nilai signifikansi 0,947>0,05, berarti tenaga kerja secara parsial tidak berpengaruh siginifikan terhadap produksi kerupuk mie singkong di Desa Cikukulu Kecamatan Karangnunggal Kabupaten Tasikmalaya.

Pengaruh Bahan Baku terhadap Produksi Kerupuk Mie Singkong di Desa Cikukulu Kecamatan Karangnunggal Kabupaten

\section{Tasikmalaya}

Hasil perhitungan SPSS 23.0 yang tersaji pada Tabel 18., memperlihatkan bahwa uji t untuk variabel bahan baku diperoleh nilai signifikansi 0,000. Berdasarkan probabilitas nilai signifikansi $0,000<0,05$, berarti bahan baku secara parsial berpengaruh siginifikan terhadap produksi kerupuk mie singkong di Desa Cikukulu Kecamatan Karangnunggal Kabupaten Tasikmalaya.

\section{KESIMPULAN DAN SARAN}

\section{Kesimpulan}

Berdasarkan hasil pembahasan, maka dapat diambil kesimpulan dalam penelitian ini yaitu faktor-faktor yang yang mempengaruhi produksi adalah modal, tenaga kerja dan bahan baku. Faktor modal, tenaga kerja dan bahan baku secara simultan berpengaruh signifikan terhadap produksi kerupuk mie singkong di Desa Cikukulu Kecamatan Karangnunggal Kabupaten Tasikmalaya. Sedangkan secara parsial faktor-faktor yang berpengaruh signifikan terhadap produksi kerupuk mie singkong yaitu modal dan bahan Baku

\section{Saran}

Berdasarkan kesimpulan dari hasil penelitian, maka disarankan sebaiknya UMKM dapat meningkatkan dan mengoptimalkan faktor modal dan tenaga kerja serta menjaga bahan baku agar dapat meningkatkan produksi produksi pada Kerupuk Mie Singkong di Desa Cikukulu Kecamatan Karangnunggal Kabupaten Tasikmalaya dengan cara meningkatkan dan mengoptimalkan modal dan tenaga kerja serta menjaga bahan baku agar dapat meningkatkan produksi

\section{DAFTAR PUSTAKA}

Agustiar. 2012 Jurnal Ilmu Pertanian Indonesia. hlm, 209-217 Vol. 16 No.3

Anorga, dkk.2002. Koperasi, Kewirausahaan, dan Usaha Kecil Jakarta: PT Rienka Cipta.

Anoraga, Pandji. 2007. Pengantar Bisnis: Pengelolaan Bisnis dalam Era Globalisasi. Jakarta: Rineka Cipta.

Amri, S., Ikhbar, S., \& Nuzakkir, M. (2016). Strategi Pengentasan Kemiskinan Melalui Produksi Usahatani 
Padi Sawah untuk Peningkatan Pembangunan Perekonomian Masyarakat Kabupaten Aceh Besar. Jurnal Serambi Saintia, Vol.4 No. 2.

Amron dan Taufiq Imran. 2009. Analisis Faktor-Faktor yang Berpengaruh Terhadap Produktivitas Tenaga kerja Outlet Telekomunikasi Seluler Kota Makassar. Jurnal Sekolah Tinggi Ilmu Ekonomi Nobel Indonesia.

Ari Sudarman. 2004, "Teori Ekonomi Mikro", edisi keempat. Yogyakarta:

BPFE Yogyakarta.

Arikunto, Suharsimi. 2010. Prosedur Penelitian Suatu pendekatan Praktek. Jakarta: Rineka Cipta.

BPS. 1999. Klasifikasikan industri berdasarkan jumlah pekerjanya. Kabupaten Tegal: Biro Pusat Statistik.

BP3K Kecamatan Karangnunggal. 2019. Data Luas Tanam, Panen, Produktivitas dan Produksi. Kabupaten Tasikmalaya.

Desa Cikukulu Kecamataan Karangnunggal.2019. Unit Usaha, Produksi, Jumlah Tenaga Kerja Industri Rumah Tangga Kerupuk Mie Singkong di Desa Cikukulu. Kecamatan Karangnunggal.

Daniel, Moehar. 2004. Pengantar Ekonomi Pertanian. Bumi Aksara: Jakarta.

Dinas Pertanian, Pangan, Perikanan Kabupaten Tasikmalaya. 2019.
Data Luas Tanam, Panen,Produktivitas Dan Peoduksi. Kabupaten Tasikmalaya

Ghozali, Imam. 2005. Aplikasi Analisis Multivariate dengan Program IBM SPSS. Yogyakarta: Universitas Diponegoro

Ghozali, Imam. 2012. Aplikasi Analisis Multivariate dengan Program IBM SPSS. Yogyakarta: Universitas Diponegoro

Kasmir, 2009. Analisis Laporan Keuangan. Penerbit PT. Raja Grafindo Persada. Jakarta.

Kholmi, Masiyal . 2003. Akuntansi Biaya Edisi Empat, Yogyakarta:BPFE

Koswara, S. 2009. Teknologi Pengolahan Singkong. Fakultas Teknologi Pertanian, Institut Pertanian Bogor, Bogor. 26 hlm

Kuncoro, Mudrajat. 2007. Ekonometrika Industri Indonesia. Yogyakarta: CV. Andi Offsite.

Lesmana, Endoy Dwi Yuda. 2014. Pengaruh Modal, Tenaga Kerja, dan Lama Usaha terhadap Produksi Kerajinan Manik-Manik Kaca. Jurnal IlmiahMahasiswa FEB, Vol. 2 No. 2.

Mawardati,2015.Analisis faktor-faktor yang mempengaruhi pendapatan usahatani pinang Kecamatan Sawang Kabupaten Aceh Utara.

Mulyadi, 2005. Sistem Akuntansi, Edisi Ketiga, Salemba Empat, Jakarta. 
Mutiara Ayu. 2010. "Tentang Analisis Bahan Baku, Bahan Bakar, dan Tenaga kerja Terhadap Produksi Tempe di Kota Semarang". Skripsi: Universitas Diponegoro Semarang.

Nasution, Rusdiah. 2008. Pengaruh Modal Kerja, Luas Lahan, dan Tenaga Kerja terhadap Pendapatan Usaha Tani Nenas (studi kasus : Desa Purba Tua Baru, Kec. Silimakuta, kab. Simalungun. Skripsi. Medan Universitas Sumatera Utara.

Puntoro dan Purwati. 2011. Budidaya delapan Jenis Tanaman Unggul. Penembar Swadaya. Jakarta.

Putong, Iskandar. 2003. Pengantar Ekonomi Mikro dan Makro. Jakarta: Ghaila Indonesia
Putong, Iskandar. 2010. Economics: Pengantar Mikro dan Makro Edisi $4 . \quad$ Jakarta: Mitra Wacana Media.

Prawirosentono, Suyadi. (2001). "Manajemen Operasi: Analisi Dan Studi Kasus". Jakarta: Bumi Aksara.

Sandi, I Made.2010. Rebuplik Indonesia Geografi Regional. Jakarta: Puri Margasari.

Soekartawi. 2006. Analisis Usahatani. Jakarta. Universitas Indonesia.

Utoyo, Bambang. 2009. Geografi (Membuka Cakrawala Dunia). Pusat Perbukuan Departemen Pendidikan Nasional.

Wirantha, I.M., 2005. Metodologi Penelitian Sosial Ekonomi. Yogyakarta: Penerbit ANDI 